\title{
Qualidade dos Ovos de Codornas Japonesas (Coturnix japonica) Alimentadas com Rações Contendo Diferentes Níveis de Glicerol
}

\author{
Quality of Japanese Quails Eggs (Coturnix japonica) Fed Diets \\ Containing Different Levels of Glycerol
}

\author{
Dênio Garcia Silva de Oliveira ${ }^{1}$, Paloma Caroliny de Melo Santos ${ }^{1}$, Janaine Viana \\ Teixeira ${ }^{1}$.
}

${ }^{1}$ Centro Universitário de Formiga (UNIFOR-MG) - Faculdade de Medicina Veterinária. Formiga, Minas Gerais, Brasil.

\begin{abstract}
Resumo
Introdução: A coturnicultura é uma atividade avícola em expansão, tendo como principal produto o ovo, que é uma fonte de proteína animal, além disso a produção dos ovos de codornas, vem crescendo intensamente nos últimos anos A utilização de subprodutos na dieta dos animais diminui custos na produção. Objetivos: O objetivo do trabalho foi avaliar a qualidade dos ovos de codornas desafiadas com rações contendo diferentes níveis de glicerol. Metodologia: O experimento foi realizado na Fazenda Laboratório do UNIFOR-MG, sendo utilizadas 72 codornas japonesas da linhagem Fujikura (Coturnix japonica), contendo apenas fêmeas. As mesmas foram subdivididas em 3 grupamentos que consistiram em ração controle, $16 \%$ e $24 \%$ de glicerol incluso a ração. Os ovos foram recolhidos e selecionados, levados ao laboratório de Tecnologia de Inspeção de Produtos de Origem Animal do UNIFOR-MG onde foram avaliados os seguintes parâmetros: peso dos ovos (g), gema (g), albúmen (g), casca (g) e a sua espessura $(\mu \mathrm{m})$, avaliação da gema e albúmen (horizontal e vertical) e o seu peso (g). Resultados: O glicerol não demostrou alterações nas codornas, da mesma forma em relação a qualidade dos ovos, não ocorrendo alterações significantes, podendo ser um substituto energético mais barato.
\end{abstract}

Palavras-chave: Coturnicultura. Glicerina. Nutrição.

Recebido em: 04/05/2016 Revisado em: 09/06/2016

Aceito em: 09/06/2016 Publicado em: 15/06/2016 


\section{Abstract}

Introduction: The cotton industry is a poultry activity expanding, the main product the egg, which is an animal protein source, furthermore the production of quail eggs has grown intensively in recent years the use of by-products in the diet of animals reduces costs in production. Objectives: The objective was to evaluate the quality of quails eggs challenged diets with different levels of glycerol. Methodology: The experiment was conducted at Fazenda UNIFOR-MG Laboratory, and used 72 Japanese quails of Fujikura lineage (Coturnix japonica), containing only females. The samples were divided into 3 groups consisting of a control diet, $16 \%$ and $24 \%$ glycerol included in the feed. The eggs were collected and selected, brought to the Inspection Technology Laboratory Animal Products of UNIFOR-MG where were assessed the following parameters: egg weight $(g)$, yolk $(g)$, albumen $(g)$, bark $(g)$ and its thickness $(\mathrm{mM})$, the yolk and albumen reviewed (horizontal and vertical) and weight (g). Results: Glycerol did not show changes in quails, the same way about the quality of eggs, no significant changes taking place and can be a cheaper energy replacement.

Keywords: Coturnicultura. Glicerina. Nutrição.

\section{Introdução}

A coturnicultura é uma atividade avícola que vem crescendo em grande escala no mercado Brasileiro, gerando um número de empregos significativo à sociedade. Além disso, tem como seu principal produto o ovo, uma fonte de proteína de alto valor biológico, da mesma forma a produção dos ovos de codornas, vem crescendo intensamente nos últimos anos.

Segundo Leandro et al. ${ }^{1}$ as codornas possuem um rápido crescimento, grande produção de ovos, pouco consumo de ração, precocidade sexual, e são resistentes a várias doenças.

A utilização de subprodutos na ração de animais, pode reduzir o custo de produção, e podendo também ocorrer um aumento na rentabilidade ${ }^{2}$. O glicerol, um subproduto do biodiesel, sempre que financeiramente rentável, pode ser administrado à ração como substituto energético do milho ${ }^{3}$. Os produtos não convencionais são um grande foco em estudos principalmente em nutrição, por serem descartados pelas indústrias e não competirem com a alimentação humana.

$\mathrm{O}$ presente trabalho consistiu em avaliar o desempenho de codornas desafiadas com rações contendo diferentes níveis de glicerol, realizando a verificação da qualidade dos ovos.

\section{Metodologia}

O trabalho foi realizado na Fazenda Laboratório do UNIFOR, com duração de 60 dias, com a utilização de 72 codornas japonesas da linhagem Fujikura (Coturnix japonica), adquiridas de criatório credenciado, possuindo apenas fêmeas com idades e pesos variados, devidamente revacinadas com Newcastle.
As mesmas foram subdivididas em 3 grupamentos experimentais, onde foram suplementas com 3 tipos de ração: Ração 1 (controle), Ração 2 (inclusão de 16\% de glicerol) e Ração 3 (inclusão de $24 \%$ de glicerol).

A distribuição das aves foi em gaiola de arame galvanizado, sendo $0,75 \mathrm{~m}^{2}$ por animal, composto de comedouros do tipo calha e bebedouros automático tipo nipple, além de aparador de excretas. A água disponibilizada ad libitum e a ração disponibilizadas ad libitum com reposição duas vezes ao dia.

As rações foram elaboradas na Fazenda Laboratório do UNIFOR, utilizando um misturador de $100 \mathrm{~kg}$, colocando cada ingrediente separado aos poucos, e por fim a adição do glicerol, logo após foram acondicionadas em tambores plásticos identificados, sendo rações isoprotéicas e isoenergéticas conforme tabela 1 . Todas formuladas à base de milho e farelo de soja, conforme adaptação de Silva ${ }^{2}$.

Os ovos foram coletados diariamente duas vezes ao dia, na parte da manhã e à tarde, respeitando os grupamentos. Após recolhidos foram selecionados, pois apenas os ovos inteiros eram analisados, e por fim foram levados ao laboratório de Tecnologia e Inspeção de Produtos de Origem Animal do UNIFOR-MG, onde foram realizadas as seguintes análises conforme descrito por Moura et $\mathrm{al}^{4}$ : peso dos ovos $(\mathrm{g})$, espessura da casca $(\mu \mathrm{m})$, avaliação da gema e albúmen (verticalmente e horizontalmente), peso da gema (g), peso do albúmen (g), peso de ambas juntas (g) e peso da casca $(\mathrm{g})$.

Os ovos foram identificados, pesados, e então quebrados, realizando a avaliação de gema e albúmen com auxílio do paquímetro digital (LEE TOOLS), e a pesagem com a balança de precisão (Coleman) de $0,01 \mathrm{~g}$, sendo pesadas então a gema e o albúmen juntos, em seguida a pesagem da gema separada, e o 
peso do albúmen foi obtido através da diferença do valor total do peso do ovo e do peso da gema. As cascas foram pesadas e aferidas através do micrometro (KINGTOOLS) com curso de $25 \mathrm{~mm}$.

O glicerol que foi utilizado no experimento é um subproduto da metilação do óleo de soja queimado na produção do biodiesel, oriundo de um projeto do curso de Engenharia Química. Os ovos e as aves ao final do experimento foram doados a entidades carentes do município de Formiga-MG.

Tabela 1 - Programa de Emagrecimento

\begin{tabular}{|c|c|c|c|}
\hline \multirow{2}{*}{ Ingredientes } & \multicolumn{3}{|c|}{ Glicerol bruto } \\
\hline & $0 \%$ & $16 \%$ & $24 \%$ \\
\hline Milho grão & 54,58 & 38,58 & 30,18 \\
\hline Farelo de soja $45 \%$ & 37,84 & 44,72 & 46,02 \\
\hline Glicerol bruto & 0,00 & 16,00 & 24,00 \\
\hline Óleo de soja & 2,88 & 0,365 & 0,09 \\
\hline Fosfato bicácico & 1,61 & 1,63 & $\mathbf{1 , 6 0}$ \\
\hline Premix & 2,23 & 2,23 & 2,20 \\
\hline Sal comum & 0,40 & 0,40 & $\mathbf{0 , 4 0}$ \\
\hline Calcário & 0,28 & 0,26 & $\mathbf{0 , 2 0}$ \\
\hline \multicolumn{4}{|c|}{ Composição nutricional } \\
\hline Proteína bruta & 23,20 & 23,20 & 23,20 \\
\hline Energia metabolizável (Kcal. Kg $^{-1}$ ) & 3.000 & 3.000 & 3.000 \\
\hline Cálcio & 0,61 & 0,61 & 0,61 \\
\hline Fósforo & 0,41 & 0,41 & $\mathbf{0 , 4 1}$ \\
\hline
\end{tabular}

\section{Resultados}

O efeito da adição do glicerol na ração para as codornas sobre a avaliação da qualidade dos ovos pode ser observada na Tabela 2. Observando os resultados, nota-se que diferenças mínimas foram notadas. Em relação ao peso dos ovos, este pequeno aumento justifica a presença do incremento calórico, influenciando também no peso da gema e albúmen e de ambas. Corroborando com os resultados Fontinele et $\mathrm{al}^{5}$ trabalhando com poedeiras comerciais e até $10 \%$ de inclusão de glicerina verificou que não houve melhora significativa no peso dos ovos, mas houve melhora significativa na massa de ovos.

Tabela 2 - Qualidade dos ovos após 60 dias.

\section{Características}

Peso Total Ovos (g)

Espessura Casca $(\mu \mathrm{m})$

Peso Gema (g)

Peso Albúmen (g)

Peso Gema e Albúmen (g)
Controle

9,6

0,22

3,5

4,0

7,5
Glicerol $16 \%$

Glicerol 24\%

Lammers et $\mathrm{al}^{6}$ utilizando até $15 \%$ de inclusão de glicerina na ração de poedeiras Hy-Line W36 mão observaram alteração na produção de ovos, massa de ovo e consumo de alimento, corroborando com os resultados obtidos no experimento.

A utilização de até $24 \%$ de inclusão de glicerina na dieta não influenciou na qualidade do ovo diferentemente de Simon, Bergner \& Schwabe ${ }^{7}$ que avaliaram inclusão de até $25 \%$ concluindo que o melhor desempenho produtivo das poedeiras foi com a inclusão de $10 \%$ de glicerina na dieta.

$\begin{array}{ll}10,2 & 9,7 \\ 0,22 & 0,20 \\ 4,0 & 4,0 \\ 5,0 & 5,0 \\ 8,0 & 8,0\end{array}$

A inclusão de até $24 \%$ de glicerol na dieta de codornas poedeiras não houve alterações na qualidade dos ovos o que não corrobora com Cerrate et $\mathrm{al}^{3}$, que verificaram efeitos negativos na carcaça de frangos de corte com a utilização de $10 \%$ de glicerol na ração, apresentando uma redução significativa no peso da carne de peito, asas e pernas, comparadas com a suplementação controle. Já no estudo de Silva et $\mathrm{al}^{2}$, a inclusão de $8 \%$ de glicerol na dieta não há alterações no ganho de peso, conversão alimentar, e o consumo de ração para as codornas de corte afirmando os resultados com codornas poedeiras. 


\section{Conclusão}

Portanto o glicerol sendo um alimento não convencional pode ser utilizado na alimentação de codornas poedeiras em substituição ao milho, sem trazer prejuízos para a qualidade dos ovos das codornas.

\section{Declaração de conflitos de interesses}

Os autores do artigo afirmam não haver nenhuma situação de conflito de interesse.

\section{Referências}

1. LEANDRO, N. S. M. et al. Desempenho produtivo de codornas japonesas (Coturnix coturnix japonica) submetidas a diferentes densidades e tipos de debicagem. Maringá, v. 27, n. 1, p. 129-135, jan./march. 2005

2. SILVA, S. C. C. et al. Expressão do mRNA de genes mitocondriais e desempenho produtivo de codornas alimentadas com glicerol. Pesq. Agropec. Bras., Brasília, v.48, n. 2, p. 228-233, fev. 2013.

3. CERRATE, S. et al. Evaluation of glycerine from biodiesel production as a feed ingredient for broilers. International Journal of Poultry Science, v.11, p.10011007, 2006.

4. MOURA, A. M. A. et al. Desempenho e qualidade do ovo de codornas japonesas alimentadas com rações contendo sorgo. Revisata Brasileira de Zootecnia, v. 39, n. 12, p. 2697-2702, 2010

5. FONTINELE, G. S. P. et al. Resultado econômico do uso da glicerina derivada do biodiesel na dieta de poedeiras semipesadas criadas no semiárido nordestino. Informações Econômicas, SP, v. 45, n. 5, set/out. 2015.

6. LAMMERS, P. et al. Nitrogen corrected apparent metabolizable energy value of crude glycerol for laying hens. Journal Animal Science, v. 87, n. 1, p. 104-107, 2008

7. SIMON, A.; BERGNER, H.; SCHWABE, M. Glycerol as feed ingredient for broiler chickens. Archives of Animal Nutrition, Berlin, 1996, v. 49, n. 2, p. 103-112. 